\title{
Factors associated with the presence of cleft lip and / or cleft palate in Brazilian newborns
}

Bianca Machado Cruz Shibukawa 1

https://orcid.org/0000-0002-7739-7881

Gabrieli Patricio Rissi 2

https://orcid.org/0000-0002-1702-4004

leda Harumi Higarashi 3

https://orcid.org/0000-0002-4205-6841

Rosana Rosseto de Oliveira 4

https://orcid.org/0000-0003-3373-1654

1-4 Departamento de Enfermagem. Universidade de Maringá. Av. Colombo, 5790. Maringa, PR, Brasil. CEP: 87.020-900. E-mail: bih.cruuz@gmail.com

\begin{abstract}
Objectives: to analyze the trend and the associated factors with the presence of cleft lip and/or cleft palate in Brazilian newborns, in order to verify possible associations with maternal care and newborn factors.

Methods: a cross-sectional and ecological study, involving all live births in Brazil, recorded in the Information System on Live Births from 2005 to 2016. Maternal and infant information were evaluated using trend analysis and odds ratio, with a $95 \%$ confidence interval. The analyses were performed using SPSS software.

Results: we analyzed 17,800 live births with presence of cleft lip and/or cleft palate. The Brazilian prevalence rate was 0.51 / 1000 live births, with South and Southeast Regions registering higher rates than the national rate. There was an association with maternal age above 35 years old, with no partner, less than seven prenatal consultations, premature birth and cesarean section. About the factors of the newborn, being male, Apgar less than seven in the 1 st and $5^{\text {th }}$ minutes of life, low birth weight and white color were associated.

Conclusions: Brazil has an increasing tendency for cleft lip and/or cleft palate $(p=0.019)$, reinforcing the need to strengthen health care networks, providing adequate support for newborn with cleft lip and/or cleft palate and their families.
\end{abstract}

Key words Cleft lip, Cleft palate, Prevalence 


\section{Introduction}

Cleft lip and/or cleft palate are the most common facial congenital malformations and have presented a trend of increase in Brazil ${ }^{1}$ and worldwide. ${ }^{2}$ In Canada, the rate of cleft lip and/or cleft palate was 1.4 per thousand live births in the year $2015,{ }^{3}$ while in the United States the rate was 3.6 in $2016.4 \mathrm{In}$ Brazil, it was found a ratio of 0.6 per thousand live births in 2017, with a growing trend of this type of malformation, mainly in the less developed regions of the country. 5

Cleft lip and/or cleft palate are due to problems in the process of development during the embryonic or fetal period, causing the disability or lack of fusion between the tissues that comprise these structures. 6 The etiology of the anomaly of lip and/or palate is still not well defined; however, studies show that between 25 and $30 \%$ of the cases are the result of hereditary factors, and 70 to $80 \%$ have a multifactorial etiology, involving among other things, maternal habits of life during pregnancy (diet, alcohol, tobacco and drugs). 1,7

Various problems arising from the presence of cleft lip and/or cleft palate may affect its patient since birth, such as difficulties in breastfeeding due to impaired sucking, swallowing and breathing; disorders in hearing and phonation, with losses in communication, in addition to the low social acceptance. The sum of these factors can result in complicating psychological, affecting both the children and their families. ${ }^{4}$

In addition, a retrospective study conducted in the Netherlands, with analysis of 5401 children with cleft lip and/or cleft palate, from 1997 to 2011, showed that the chance of mortality in infants with these presences alone is 2.07 times higher than in those without any type of congenital anomalies. ${ }^{8}$

Considering, in this way, the importance of the theme for the society, the growing trend of this anomaly and the shortage of recent national studies, we aimed to analyze the trend and the factors associated with the presence of cleft lip and/or cleft palate in Brazilian neonates. In this way, it is intended to bring out an analysis in Brazil and by regions, associations of cleft lip and/or cleft palate with care, maternal and pediatrics factors.

\section{Methods}

A cross-sectional study of ecological character considering all live births of residents in Brazil, recorded based on data from the Information System on Live Births (Sinasc), in the period from 2005 to
2016.

The database used for collection, the Sinasc, lodges itself on the platform of the Department of Informatics of the Single Health System (DATASUS) and aims to collect epidemiological information on births in Brazil.

Namely, Brazil figures as the country with the largest extension in Latin America and the fifth largest in the world. As population projection for 2019 , it has an estimated population of $210,147,125$ inhabitants distributed in 26 Federal Units and the Federal District, forming five regions: North, Northeast, Midwest, Southeast and South. ${ }^{9}$

For data collection, Sinasc database for Brazil and its regions was consulted, selecting, in the field "type of congenital anomaly", the option "cleft lip and cleft palate", which have the code Q-35 and Q37 , respectively, in the International Classification of Diseases, 10th edition (ICD-10). It was also raised maternal information such as age $(<19,20$ to 34 years old, $\geq 35$ ); schooling ( $<12$ years of studies, $\geq 12$ years of study), marital status (with partner and without a partner) and gestational age ( $<37$ weeks, $\geq 37$ weeks). For analysis of the care factor, the number of pre-natal consultations was verified $(<7$ consultations, $\geq 7$ consultations); and the variables of the newborn collected were: birth way (normal or cesarean section), the gender of the child (male and female), Apgar score at the 1 st and 5 th minutes of life $(<7, \geq 7)$, race/color (white and non-white) and birthweight $(<2,500$ grams, $\geq 2,500$ grams $)$.

For the calculation of prevalence rates of newborn infants with cleft lip and/or cleft palate, it was performed the ratio between the number of live births with cleft by the total number of live births in the same year and location, multiplied by 1000 .

The trend analysis using the polynomial regression model, in which the rates of newborn infants with cleft lip and/or cleft palate were considered as dependent variables (y) and the years of study as independent variable. The variable 'year' was changed into the variable year-centralized (x2010) and the series were smoothed by means of quarterly moving average of three points. The polynomial linear regression model, the quadratic and cubic models were tested. It is considered a significant tendency, one whose estimated model obtained $p<0.05$. For the choice of the best model there was still considered the analysis of the dispersion diagram, the value of the coefficient of determination $\left(r^{2}\right)$ and analysis of residues (assumption of true homoscedasticity). When all the criteria were significant for more than one model and the coefficient of determination was similar, we chose the simplest 
model, the linear regression.

The analysis of associated factors was performed through the calculation of the odds ratio (OR), with $95 \%$ confidence interval (CI) of $95 \%$, with the data grouped by regions and quadrennials (2005-2008, 2009-2012 and 2013-2016). The analyzes were performed by means of the SPSS software, version 20.1 .

The study was exempt from ethical appraisal by the Standing Committee on Ethics in Research involving humans under the letter $\mathrm{N} 08 / 2018$, on the basis of the Resolutions 466/12 - NHC/MoH 10 and $510 / 2016-\mathrm{NHC} / \mathrm{MoH},{ }^{11}$ because of being a database of unrestricted public domain.

\section{Results}

17,800 live births of children with cleft lip and/or cleft palate residents in Brazil were analyzed. The Brazilian average rate found in the study in the period from 2005 to 2016 for cleft lip and/or cleft palate was $0.51 / 1000$ live births, being that the South and Southeast regions showed average rates higher than the Brazilian average $(0.72 / 1000$ and $0.54 / 1000$ live births, respectively). The lowest average rates were observed in the Northeast $(0.39 / 1000$ live births) and North (0.45/1000 live births).

As regards the rates of cleft lip and/or cleft palate in Brazil and regions, in 2005 the national rate was of $0.52 / 1000$ alive newborns, increasing to $0.56 / 1000$ in 2016, with greater involvement of the Southern Region, which went from $0.73 / 1000$ in 2005 to $0.68 / 1000$ alive newborns in 2013. In relation to the period studied, we observed oscillations in the values of rates of cleft lip and/or cleft palate, being 2006 the year with the lowest rate in the Northeast Region (0.31/1000 alive newborns), and the highest rate found in 2010 in the South Region $(0.79 / 1000)$ (Figure 1).

Regarding the analysis of polynomial regression, there was a trend of increasing rates of cleft lip and/or cleft palate in Brazil $\left(0.008 ; r^{2}=0.59\right)$, with the highest average annual increase in the Northeast Region $\left(0.015 ; r^{2}=0.90\right)$ and a growing trend in the Southeastern Region (0.008; $\left.r^{2}=0.51\right)$. Another alarming factor is that the South Region, holder of the highest rates of cleft lip and/or cleft palate, remained constant. The Midwest region showed increasing rates of cleft until the year of 2011 with a subsequent decrease of rates, but with a new increase in the year of 2016 (Table 1).

In relation to maternal factors of newborn infants with cleft lip and/or cleft palate, we observed that women of 35 years old or older had more chances of having a child with cleft lip and/or cleft palate than those that do not fit in this age $(\mathrm{OR}=1.30$ in the quadrennium of 2013-2016). Regarding the presence of companion, women without a partner showed a protective factor $(\mathrm{OR}=0.90)$ in the period 2005-2008 and 2013-2016, without statistical significance in the period 2009-2012. The variable schooling also showed no significant statistical results (Table 2).

In relation to care factors, insufficient number of pre-natal consultations was present with statistical significance only in the quadrennium of 2005 to 2008 ( $p=0.011)$. The gestational age at birth less than 37 weeks, showed to be associated with cleft lip and/or cleft palate in the three quadrennium analyzed $(p<0.001)$, being that premature babies were, on average, two times more likely to be born with cleft lip and/or cleft palate. For the track of birth, babies with cleft lip and/or cleft palate were 1.2 times more likely to be born of cesarean sections $(p<0.001)$ than that of normal birth (Table 2).

In addition, it is necessary to recognize the profile of babies born with cleft lip and/or cleft palate. In babies with cleft lip and/or cleft palate, it is noticed that they are two times more likely $(p<0.001)$ to achieve less than seven points in the scale of Apgar score in the first minute and four times more likely $(p<0.001)$ in the fifth minute of life, compared to children who did not have cleft lip and/or cleft palate. In addition, male babies were 1.3 times more likely $(p<0.001)$ to develop fissures when compared to females (Table 3).

Another factor that proved to be of extreme importance was the birth weight, so that babies who were born with low birth weight in the three quadrennials analyzed, were approximately 2.5 times more likely $(p<0.001)$ of having fissures than children born with weights greater than 2,500 grams.

As regards the race/color of babies, the nonwhite color presented a protective factor regarding the development of cleft lip and/or cleft palate, being that these registered approximately 0.80 times more chances $(p<0.001)$ of not presenting fissure than white babies.

\section{Discussion}

The results are consistent with data found in the literature, pointing to the significant increase in the birth of Brazilian neonates with cleft lip and/or cleft palate. The presence of cleft was associated with prematurity, race/color white, children of mothers with age greater than or equal to 35 years old and worse conditions of vitality at birth.12-16

The average rate of cleft lip and/or cleft palate 


\section{Figure 1}

Distribution of cleft lip and/or palate rates of newborns, according to the Brazilian region. Brazil, 2005 to 2016.

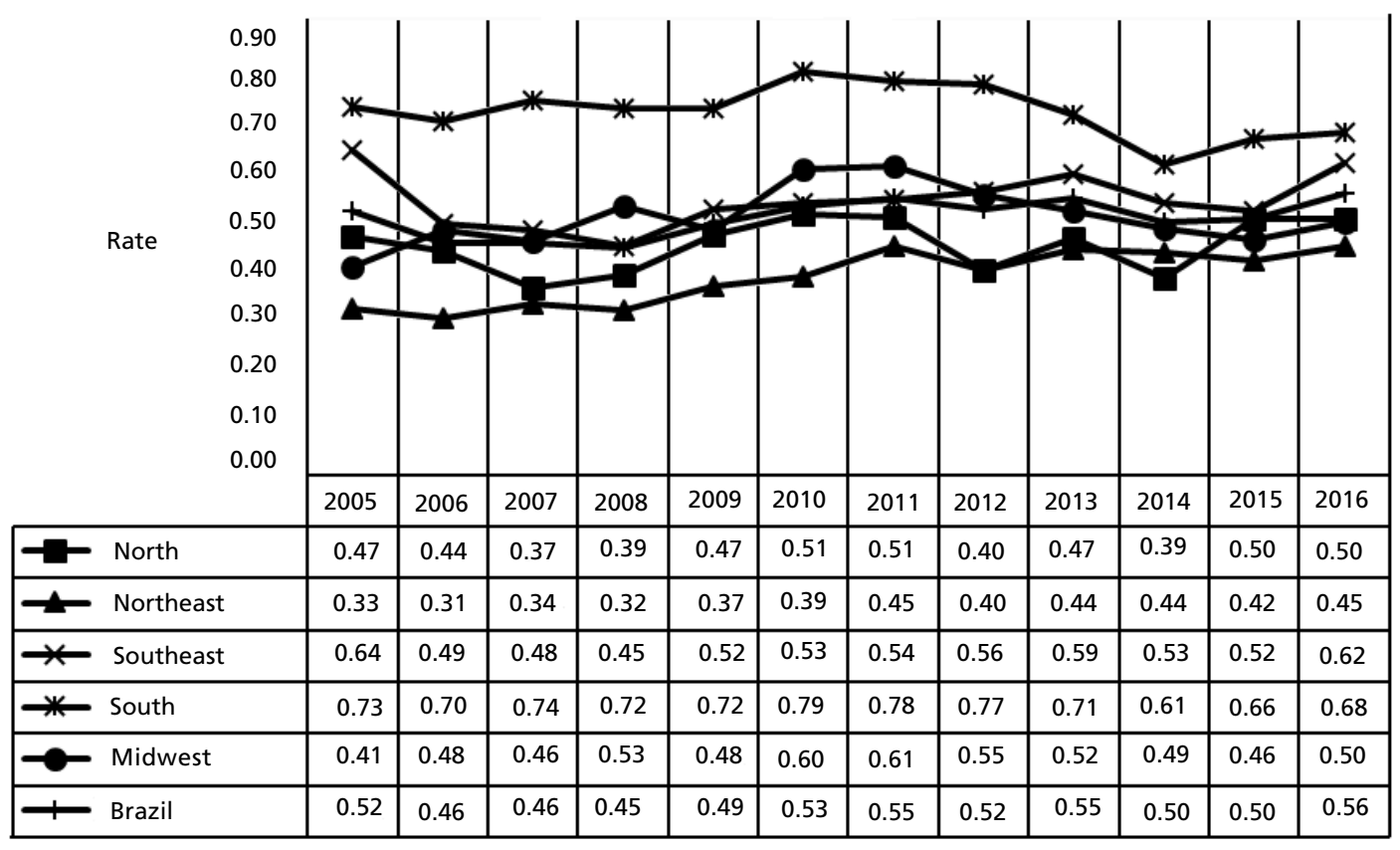

Table 1

Tendency of cleft lip and/or palate rates in newborns, according to the Brazilian region. Brazil, 2005 to 2016.

\begin{tabular}{lcccc}
\hline & \multicolumn{1}{c}{ Model } & $\mathbf{R}^{2}$ & $\boldsymbol{p}$ & Trend \\
\hline Brazil & $\mathrm{y}=0.50+0.008 \mathrm{x}$ & 0.59 & 0.009 & Ascending \\
North & $\mathrm{y}=0.44+0.004 \mathrm{x}$ & 0.19 & 0.213 & Ascending \\
Northeast & $\mathrm{y}=0.38+0.015 \mathrm{x}$ & 0.90 & $<0.001$ & Ascending \\
Southeast & $\mathrm{y}=0.53+0.008 \mathrm{x}$ & 0.51 & 0.019 & Ascending \\
South & $\mathrm{y}=0.72-0.007 \mathrm{x}$ & 0.25 & 0.143 & Ascending \\
Midwest & $\mathrm{y}=0.55+0.008 \mathrm{x}-0.005 \mathrm{x}^{2}$ & 0.85 & 0.001 & Ascending/Descending
\end{tabular}


Table 2

Association of maternal and care factors of newborns with cleft lip and/or palate. Brazil, 2005 to 2016.

\begin{tabular}{|c|c|c|c|c|c|c|c|c|c|c|c|c|}
\hline & \multicolumn{4}{|c|}{$2005-2008$} & \multicolumn{4}{|c|}{$2009-2012$} & \multicolumn{4}{|c|}{$2013-2016$} \\
\hline & $\mathrm{n}$ & $\%$ & OR & $\mathrm{Cl} 95 \%$ & $\mathrm{n}$ & $\%$ & OR & $\mathrm{Cl} 95 \%$ & $\mathrm{n}$ & $\%$ & OR & $\mathrm{Cl} 195 \%$ \\
\hline \multicolumn{13}{|l|}{ Maternal age (years) } \\
\hline$\leq 19$ & 1102 & 19.8 & 1.00 & $1.03-0.90$ & 1136 & 18.8 & 1.00 & $1.07-0.94$ & 1056 & 17.1 & 1.00 & $1.02-0.89$ \\
\hline $20-34$ & 3727 & 67.0 & & & 4083 & 67.4 & & & 4127 & 66.7 & & \\
\hline$\geq 35$ & 728 & 13.1 & 1.40 & $1.30-1.52$ & 836 & 13.8 & 1.30 & $1.24-1.44$ & 1003 & 16.2 & 1.30 & $1.25-1.43$ \\
\hline Ignored & 2 & - & - & - & - & - & - & - & - & - & - & - \\
\hline \multicolumn{13}{|c|}{ Schooling (years of study) } \\
\hline$<8$ & 2398 & 43.1 & & & 2009 & 33,2 & 1.0 & $0.98-1.09$ & 1529 & 24.7 & 1.1 & $1.03-1.15$ \\
\hline$\geq 8$ & 3051 & 54.9 & 10.0 & $9.56-10.43$ & 3974 & 65.6 & & & 4591 & 74.2 & & \\
\hline Ignored & 110 & 2 & & & 72 & 1.2 & & & 66 & 1.1 & & \\
\hline \multicolumn{13}{|l|}{ Marital status } \\
\hline With companion & 2194 & 39.4 & & & 2737 & 45.2 & & & 3603 & 58.2 & & \\
\hline No companion & 3269 & 58.8 & 0.90 & $0.97-0.87$ & 3267 & 53.9 & 1.00 & $1.01-0.91$ & 2525 & 40.8 & 0.90 & $0.99-0.89$ \\
\hline Ignored & 96 & 1.7 & & & 51 & 0.8 & & & 58 & 0.9 & & \\
\hline \multicolumn{13}{|c|}{$\mathrm{N}^{\circ}$ of prenatal consultations } \\
\hline$<7$ & 2328 & 41.8 & 0.90 & $0.98-0.88$ & 2334 & 38.5 & 1.00 & $1.05-0.95$ & 2150 & 34.8 & 1.00 & $0.98-1.09$ \\
\hline$\geq 7$ & 3150 & 56.6 & & & 3656 & 60.4 & & & 3988 & 64.5 & & \\
\hline Ignored & 81 & 1.5 & & & 65 & 1.1 & & & 48 & 0.8 & & \\
\hline \multicolumn{13}{|c|}{ Gestational age (weeks) } \\
\hline$<37$ & 734 & 13.2 & 2.10 & $1.99-2.32$ & 978 & 16.2 & 1.90 & $1.82-2.08$ & 1115 & 18.0 & 1.70 & $1.63-1.86$ \\
\hline$\geq 37$ & 4758 & 85.6 & & & 4962 & 81.9 & & & 4946 & 79.9 & & \\
\hline Ignored & 67 & 1.2 & & & 115 & 1.9 & & & 125 & 2.0 & & \\
\hline \multicolumn{13}{|l|}{ Type of parturition } \\
\hline Normal & 2724 & 49.0 & & & 2630 & 43.4 & & & 2473 & 39.9 & & \\
\hline Cesarean & 2829 & 50.9 & 1.20 & $1.16-1.29$ & 3414 & 56.4 & 1.20 & $1.09-1.21$ & 3695 & 59.7 & 1.20 & $1.11-1.23$ \\
\hline Ignored & 6 & 0.1 & & & 11 & 0.2 & & & 18 & 0.3 & & \\
\hline
\end{tabular}


$\stackrel{\circ}{\text { N Table } 3}$

Association of factors of newborns with cleft lip and/or palate. Brazil, 2005 to 2016.

\begin{tabular}{|c|c|c|c|c|c|c|c|c|c|c|c|c|}
\hline & \multicolumn{4}{|c|}{$2005-2008$} & \multicolumn{4}{|c|}{$2009-2012$} & \multicolumn{4}{|c|}{$2013-2016$} \\
\hline & $\mathrm{n}$ & $\%$ & OR & $\mathrm{Cl} 95 \%$ & $\mathrm{n}$ & $\%$ & OR & $\mathrm{Cl} 95 \%$ & $\mathrm{n}$ & $\%$ & OR & Cl95\% \\
\hline \multicolumn{13}{|c|}{ Apgar 1 st minute } \\
\hline$\leq 7$ & 1412 & 25.4 & 1.80 & $1.71-1.93$ & 1415 & 23.4 & 1.90 & $1.77-2.00$ & 1438 & 23.2 & 2.10 & $2.01-2.26$ \\
\hline$>8$ & 3941 & 70.9 & & & 4516 & 74.9 & & & 4653 & 75.2 & & \\
\hline Ignored & 206 & 3.7 & & & 124 & 2.1 & & & 95 & 1.5 & & \\
\hline \multicolumn{13}{|c|}{ Apgar $5^{\text {th }}$ minute } \\
\hline$\leq 7$ & 483 & 8.7 & 3.10 & $2.81-3.35$ & 501 & 8.3 & 3.40 & $3.11-3.70$ & 538 & 8.7 & 4.00 & $3.73-4.39$ \\
\hline$>8$ & 4868 & 87.6 & & & 5425 & 89.6 & & & 5557 & 89.8 & & \\
\hline Ignored & 208 & 3.7 & & & 129 & 2.1 & & & 91 & 1.5 & & \\
\hline \multicolumn{13}{|l|}{ Gender } \\
\hline Female & 2344 & 42.2 & & & 2482 & 41.0 & & & 2529 & 40.9 & & \\
\hline Male & 3207 & 57.7 & 1.30 & $1.23-137$ & 3556 & 58.7 & 1.40 & $1.30-1.44$ & 3639 & 58.8 & 1.40 & $1.30-1.44$ \\
\hline Ignored & 8 & 0.1 & & & 17 & 0.3 & & & 18 & 0.3 & & \\
\hline \multicolumn{13}{|l|}{ Weight (g) } \\
\hline$<2.500$ & 995 & 17.9 & 2.40 & $2.29-2.62$ & 1102 & 18.2 & 2.40 & $2.26-2.57$ & 1154 & 18.6 & 2.50 & $2.34-2.64$ \\
\hline$>2.500$ & 4539 & 81.6 & & & 4950 & 81.7 & & & 5030 & 81.3 & & \\
\hline Ignored & 25 & 0.5 & & & 3 & - & & & 2 & - & & \\
\hline \multicolumn{13}{|l|}{ Race } \\
\hline White & 3064 & 55.1 & & & 2970 & 49.1 & & & 2587 & 41.8 & & \\
\hline Non white & 2205 & 39.7 & 0.70 & $0.71-0.64$ & 2861 & 47.2 & 0.80 & $0.08-0.72$ & 3399 & 54.9 & 0.80 & $0.82-0.74$ \\
\hline Ignored & 290 & 5.2 & & & 224 & 3.7 & & & 200 & 3.2 & & \\
\hline
\end{tabular}


was $0.51 / 1000$ live births; corroborating an analysis carried out in the period from 2000 to 2013 that pointed to a national average of $0.48 / 1000$ live births. ${ }^{13}$ As regards the Brazilian regions most affected by this anomaly, the South and Southeast regions presented higher rates, a fact that is consistent with the literature, in which the higher prevalence of cleft lip and/or cleft palate in Brazil was verified in the South region, being the lowest rate corresponding to the northeast region. ${ }^{17}$ However, it should be noted that, as evidenced in the results, the Northeast region presents an increasing trend for the development of anomaly, which can be explained by the improvement in the notifications of data also in this region. ${ }^{17}$

In the period covered by the study, Brazilian rates of cleft lip and/or cleft palate showed an increasing trend, as has already been pointed out in studies conducted with data until 2013,13 and in a similar manner to other countries such as the Netherlands 9 and Argentina. 18 In Brazil, the Northeastern and Southeastern regions also showed ascending rates, while the Midwest region showed discordant behavior to other regions with increasing rates, followed by a decreasing trend.

In spite of the reliability of the data provided by the Sinasc, 14 the discrepancy of rates found in the regions of the country, as well as between the years of study, can also be attributed to the rotation of health professionals, 19 which many times are not oriented as to the correct filling of the statement of live birth; thus impacting on the quality of the data logging. Thus, we stress the importance of awareness and empowerment of these professionals facing the proper completion of the information that feed the databases available for the population.

In relation to maternal age, the age greater than or equal to 35 was also found in a case-control study conducted in Iran, with 187 children, as a risk factor for fissure, 15 as well as in a Brazilian study. 13 Growing scientific evidence indicating that the advanced maternal age is a factor associated with the development of congenital anomalies. 16,20 This is due to the aging of the ovules, which may have structural defects due to advanced age. ${ }^{16,20}$ Another factor influencer are the pre-existing chronic diseases, which may weaken the proper functioning of the female body, causing damage to the fetus. 16,20

However, paradoxically, we found a case-control study conducted with 340 babies in Vietnam, which pointed out as the age group most affected, the population aged up to 24 years old. ${ }^{21}$ In Argentina, a casecontrol study with 13,444 babies also showed that women aged less than 19 had more chances of presenting children with cleft lip and/or cleft palate. 18 It is understood that the association between maternal age and development of cleft has controversies in the literature, although the results of this study have pointed out a higher risk of malfunction in mothers of advanced age. A hypothesis for such discrepancies in relation to the maternal age may be related to possible methodological differences in the studies, or even the confounding factors of populations under study, which may not have been identified and/or adequately controlled in the execution of data analysis.

In this study, the variable low schooling presented itself as a protective factor in the quadrennium 2005-2008, but it is known that the lack of information is an aggravating factor in health, being the low schooling a predominant Brazilian feature in the profile of neonatal deaths. $5,6,21 \mathrm{It}$ is emphasized that, from 2009 to 2016, the low schooling was demonstrated as a risk to the fissure, corroborating the literature. 22 In Argentina it was found that the maternal and paternal schooling are also considered risk factors for fissures, 18 as well as in Vietnam, where the low schooling is associated with higher chances of fissure. 21

With respect to the presence of a companion, this study indicated that the absence of a partner is associated with cleft lip and/or cleft palate, thus ratifying, findings from other studies.7-23

Another factor-associated care to children with cleft lip and/or cleft palate is the insufficient number of prenatal consultations, lower than the recommended minimum of seven. The quality and quantity of pre-natal consultations are essential for maternal and child safety, as they are linked directly with the rates of neonatal death. ${ }^{22}$ In the same direction, it is known that infants with cleft lip and/or cleft palate have more chances of being born premature, as pointed conclusions of a study of Brazilian systematic review. ${ }^{23}$ This fact can be directly connected to the type of parturition chosen for the birth, because cesarean sections for convenience do not comply with the maturity of the baby, causing the occurrence of premature infants present ascending rates. ${ }^{23}$

The results found here allow affirming that not always the number of pre-natal consultations is connected to low adherence of pregnant women, since, considering the cleft lip and/or cleft palate as a risk factor for prematurity, pregnancy can be interrupted prematurely. However, this does not justify the failure to carry out the minimum number recommended, because, since diagnosed, the baby with cleft lip and/or cleft palate demand greater monitoring and attention, as well as the family that also 
requires care and guidance.

In relation to the type of birth, it was possible to verify that children with presence of cleft lip and/or cleft palate were predominantly born by cesarean section. Given this scenario, it is observed that the cesarean section has been performed without clinical indication, many times, under the pretext of providing greater security and comfort for the parturient. ${ }^{24}$ Brazil is internationally recognized as the country with the highest rates of cesarean sections in the world, and approximately $40 \%$ in the public sector and 80 to $95 \%$ in the private sector. 25

In respect to the Apgar score at the $1^{\text {st }}$ and the $5^{\text {th }}$ minutes, no studies were found that would confirm the findings of the present study. It is known that babies who presented evaluation by the Apgar score lower than seven in the $1^{\text {st }}$ and the $5^{\text {th }}$ minutes revealed more chances to evolve to the death of that babies with scores above eight, 22 reinforcing the need of offering assistance quality at the moment of birth, aiming at the reduction of risk of death of babies with cleft lip and/or cleft palate.

The male gender as a risk factor for cleft lip and/or cleft palate, contrary to race/skin color, which is a protective factor for the development of anomaly, confirm the findings in national and international studies, which also point to the female gender as a protective factor and on the other hand the white, yellow and indigenous races as being those with greater predominance of anomaly.22,23

A study carried out in parallel with the data from the last census in Brazil, showed that there is no significant difference in the number of births among white and mixed breeds in Brazilian population, being represented by $41 \%$ and $47 \%$, respectively. 24 Therefore, it is important to investigate whether the protective factor linked to the non-white race/color is not associated to regional differences and ethnic groups in Brazil, which strengthens the possibility of a protective factor in race/non-white color.

In addition, the greater prevalence of births with cleft lip and/or cleft palate is on the Asiatic and American continents, representing 1/500 births; while, in African populations, the prevalence of the anomaly that configures in $1 / 2500$ live births, ${ }^{17}$ reinforcing the results of this study that bring the nonwhite race/color as a protective factor for the occurrence of cleft lip and/or cleft palate in Brazil.

Low birth weight pointed out as a risk factor also reinforces the findings of the literature, a fact that can be explained by the birth route is chosen, because the majority of babies with cleft lip and/or cleft palate born of scheduled cesarean births, which means that not always are already ripe for the birth, being removed from the intrauterine life before the stage of weight gain. 25,26

Finally, it is worth noting that a multi and interdisciplinary team, with a view to ensuring that it can enjoy all the features of treatment available, must follow the development of a child with cleft lip and/or cleft palate. It is important to consider that, once the treatment has started, properly and early, the chances of the baby with cleft lip and/or cleft palate has a development with quality of life are amplified.25-27

Some limitations related to the use of secondary data, may derive from the incompleteness in relation to filling or underreporting, especially in the case of an ecological study, comparing different regions in Brazil. We yet stress the impossibility of access to additional data, as a division of the disease in syndromic and non-syndromic, as well as maternal habits, which could contribute to the study, but are not available for the whole country. However, it should be emphasized that information systems are fundamental to the development of researches of greater inclusiveness, as those who seek to trace the outline of a phenomenon at the national level. We yet reinforce the need for new regional studies with different approaches in an attempt to higher compression of the findings.

In conclusion, the need of strengthening and creation of new networks of health attention for the person with cleft lip and/or cleft palate, especially in regions with a growing trend in the prevalence of this disease is emphasized. It is necessary that the professionals are prepared to promote the adequate care to the baby with cleft lip and/or cleft palate and their families, aiming to provide assistance and qualified information since the prenatal, parturition and postpartum, and early identification and monitoring of the baby with cleft lip and/or cleft palate, so that the family feel safe and quiet with the new situation which will be experienced. It is suggested to conduct further studies on this theme, strengthening the knowledge about an issue which is so important.

\section{Authors' contribution}

Shibukawa BMC participated in all steps (design and planning, data collection, analysis and data interpretation; writing and enlisting of the article). Rissi GP realized data collection, data analysis and interpretation; writing and drafting of the article. Higarashi IH participated of design and planning. Oliveira RR participated of design and planning, analysis and interpretation of data. All authors approved the final version of the manuscript. 


\section{References}

1. Lima LS, Ribeiro GS, Aquino SN, Volpe FMM, Martelli DRB, Swerts MSO, Paranaíba LMR, Júnior Martinelli H. Prevalência de sintomas depressivos em pacientes com fissuras labiopalatinas. Braz J Otorhinolaryngol. 2015; 81 (2): 177-83.

2. World Health Organization. Oral health, Information sheet of WHO, Genebra, Abril de 2012. Genebra; 2012. (WHO, Information sheet).

3. Matthews JLK, Oddone-Paolucci E, Harrop RA. The Epidemiology of Cleft Lip and Palate in Canada, 1998 to 2007. Cleft Palate-Craniofacial J. 2015; 52 (4): 417-24.

4. Santos LB. As experiências com a fissura labiopalatal e os processos de estigmatização [dissertação]. Salvador: Universidade Federal da Bahia; 2016.

5. Sousa GFT, Roncalli AG. Orofacial clefts in Brazil and surgical rehabilitation under the Brazilian National Health System. Braz Oral Res. 2017; 31: e23.

6. Holzinger ER, Li Q, Parker MM, Hetmanski JB, Marazita ML, Mangold E, Ludwig KU, Taub MA, Begum F, Murray JC, Albacha-Hejazi H, Alqosayer K, Al-Souki G, Albasha Hejazi A, Scott AF, Beaty TH, Bailey-Wilson JE. Analysis of sequence data to identify potential risk variants for oral clefts in multiplex families. Mol Genet Genomic Med. 2017; 5(5):570-9.

7. Nunem DPF, Boogaard MJH, Griot JPWD, Ruttermann M, Veken LT, Breugem CC. Elevated Infant Mortality Rate among Dutch Oral Cleft Cases: A Retrospective Analysis from 1997 to 2011. Front Surg. 2014; 48 (1): 1-4.

8. Brasil. Ministério da Saúde. Departamento de Informática do Sistema Único de Saúde. Sistema de Informação de Nascidos Vivos [online]. Brasília, Brasil; 2019. [acesso 20 mai 2019]. Disponível em: http://www2.datasus.gov.br/ DATASUS/ index.php?area $=060702$.

9. Brasil. Fundação Instituto Brasileiro de Geografia e Estatística (IBGE). Projeção da população. Resolução $n^{\circ} 3$, de 26 de agosto de 2019. Diário Oficial da União 28 ago 2019; Seção 1.

10. Conselho Nacional de Saúde (Brasil). Resolução No 466, de 16 de dezembro de 2012. Diário Oficial da União 12 jun 2013; Seção 1.

11. Conselho Nacional de Saúde (Brasil). Resolução No 510, de 07 de abril de 2016. Diário Oficial da União 98 mai 2016; Seção 1.

12. Abreu MHNG, Lee KH, Luquetti DV, Starr JR. Temporal trend in the reported birth prevalence of cleft lip and/or cleft palate in Brazil, 2000 to 2013. Birth Defects Res Part A Clin Mol Teratol. 2016; 106 (9): 789-92.

13. Coutinho ALF, Lima MC, Kitamura MAP, Neto JF, Pereira RM. Epidemiological characteristics of patients with orofacial clefts attending a Referral Center in Northeast Brazil. Rev Bras Saúde Matern Infant. 2009; 9 (2): 149-56.

14. Gabriel GP, Chiquetto L, Morcillo AM, Carmo Ferreira M do, Bazan IGM, Daolio LD, Lemos JJR, Carniel EF. Avaliação das informações das Declarações de Nascidos Vivos do Sistema de Informação sobre Nascidos Vivos (Sinasc) em Campinas, São Paulo. Rev Paul Pediatr. 2014; 32 (3): 183-8.
15. Cosme HW, Lima LS, Barbosa LG, Cosme HW, Lima LS, Barbosa LG. Prevalência de anomalias congênitas e fatores associados em recém-nascidos do município de São Paulo no período de 2010 a 2014. Rev Paul Pediatr. 2017; 35 (1): $33-8$.

16. Alves NCC, Feitosa KMA, Mendes MES, Caminha MFC. Complicações na gestação em mulheres com idade maior ou igual a 35 anos. Rev Gaúcha Enferm. 2017; 38 (4): e2017-0042.

17. Silva HPV, Arruda TTS, Souza KSC, Bezerra JF, Leite GCP, Brito MEF, Gualberto VM, Lima DM, Luchessi AD, Bortolin RH, Ururahi MAG, Rezende AA. Risk factors and comorbidities in Brazilian patients with orofacial clefts. Braz. Oral Res. 2018; 32: e24.

18. Oliveira RM, Leitao IMT de A, Aguiar LL, Oliveira AC de S, Gazos DM, Silva LMS da, Barros AA, Sampaio RL. Evaluating the intervening factors in patient safety: focusing on hospital nursing staff. Rev da Esc Enferm da USP. 2015; 49 (1): 104-13.

19. Jamilian A, Sarkarat F, Jafari M, Neshandar M, Amini E, Khosravi S, Ghassemi A. Family history and risk factors for cleft lip and palate patients and their associated anomalies. Stomatol Balt Dent Maxillofac J. 2017; 19 (3): 78-83.

20. Dien VHA, McKinney CM, Pisek A, Pitiphat W. Maternal exposures and risk of oral clefts in South Vietnam. Birth Defects Res. 2018; 110 (6): 527-37.

21. Gaiva MAM, Fujimori E, Sato APS, Gaiva MAM, Fujimori E, Sato APS. Maternal and child risk factors associated with neonatal mortality. Texto Context - Enferm 2016; 25 (4): e2290015.

22. Farinhas GV. Os sentidos produzidos nos discursos de mães frente ao nascimento de filhos com malformação labiopalatal e os recursos da rede do SUS disponibilizados para o cuidado [dissertação]. Santa Cruz do Sul: Universidade de Santa Cruz do Sul; 2017.

23. Domingues RMSM, Dias MAB, Nakamura-Pereira M, Torres JA, d'Orsi E, Pereira APE, Schilithz AOC, Leal MC. Processo de decisão pelo tipo de parto no Brasil: da preferência inicial das mulheres à via de parto final. Cad Saúde Pública. 2014; 30 (supl. 1): S101-16.

24. Caldas ADR, Santos RV, Borges GM, Valente JG, Portela MC, Marinho GL. Infant mortality according to color or race based on the 2010 Population Census and national health information systems in Brazil. Cad. Saúde Pública. 2017; 33 (7): e00046516.

25. Hemati Z, Abbasi S, Paki S, Kiani D. The Effect of Happiness Training Based on Fordyce Model on Perceived Stress in the Mothers of Children with Cleft Lip and Palate. Tabriz Univ Med Sci. 2017; 6 (2): 173-81.

26. Magne F, Puchi Silva A, Carvajal B and Gotteland M. The Elevated Rate of Cesarean Section and Its Contribution to Non-Communicable Chronic Diseases in Latin America: The Growing Involvement of the Microbiota. Front. Pediatr. 2017; 5: 192. 
27. Silva TP, Silva MM, Silva LJ, Silva IR, Leite JL.

Especificidades contextuais do cuidado de enfermagem a

criança em condição crônica hospitalizada. Ciênc Cuid Saúde. 2015 ; 14 (2): 1082-90.

Received on October 25, 2018

Final version presented on June 17, 2019

Approved on July 2, 2019 